\title{
ERRATUM
}

\section{Quinidine Pharmacokinetics in Man: Choice of a Disposition Model and Absolute Bioavailability Studies}

\author{
Theodor W. Guentert, Nicholas H. G. Holford, Peter E. Coates, \\ Robert A. Upton, and Sidney Riegelman
}

Received Dec. 5, 1979

In this article (Vol. 7, No. 4, 1979, pp. 315-330) the $V_{d_{\text {area }}}$ values reported have been miscalculated because of programming error. The correct $V_{d_{\text {area }}}$ can be readily obtained by dividing clearance by $\beta$ (Table I). The coefficient of variation within individuals taking the repeated quinidine doses (p. 324) was $47 \%, 25 \%, 7.3 \%$ for $V_{d_{\text {area }}}$ and $24 \%, 30 \%, 8.7 \%$ for clearance. 